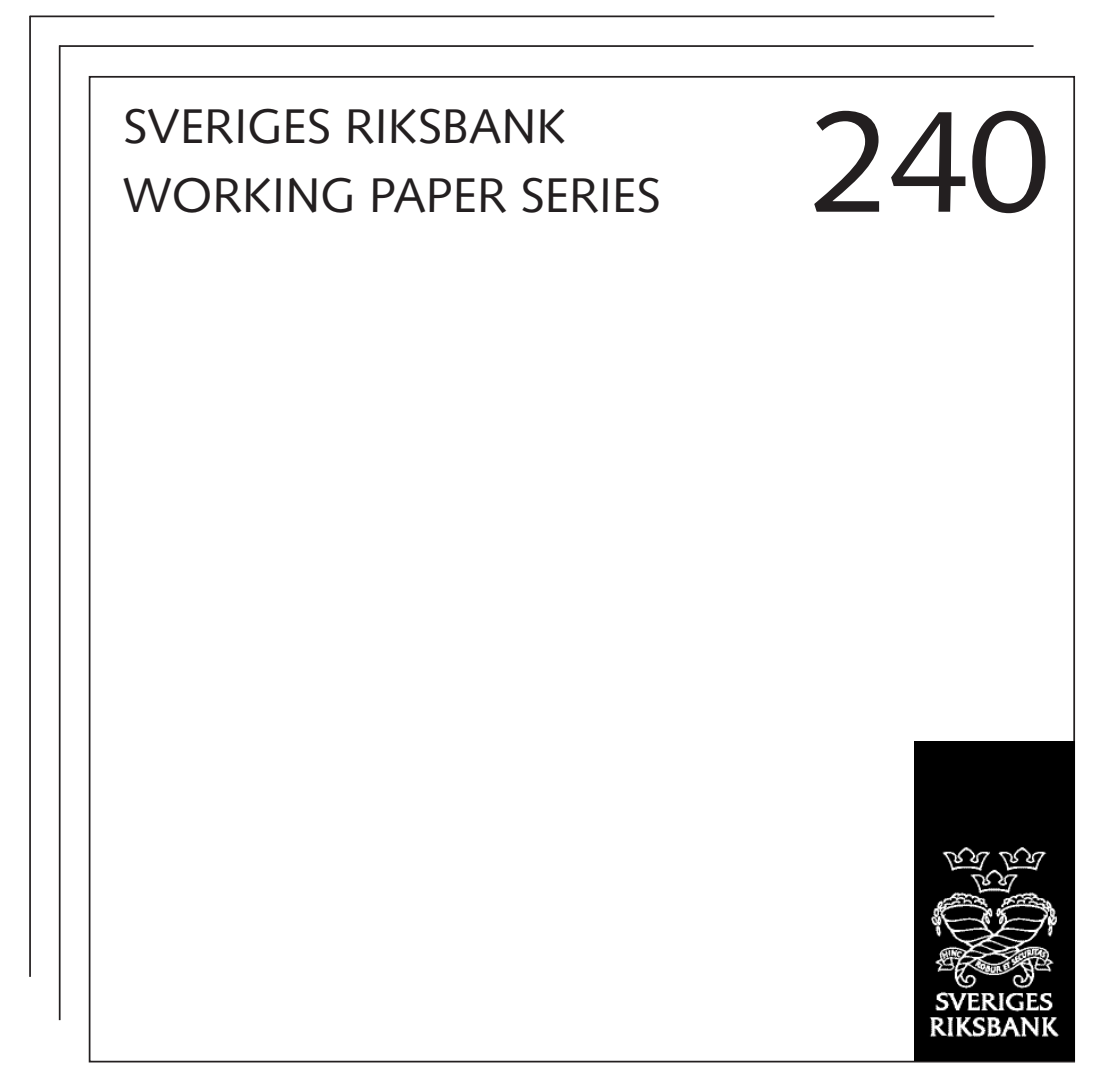

\title{
The Discursive Dilemma in Monetary Policy
}

Carl Andreas Claussen and Øistein Røisland 


\section{WORKING PAPERS ARE OBTAINABLE FROM}

Sveriges Riksbank •Information Riksbank • SE-103 37 Stockholm Fax international: +4687870526

Telephone international: +4687870100

E-mail: info@riksbank.se

The Working Paper series presents reports on matters in the sphere of activities of the Riksbank that are considered to be of interest to a wider public.

The papers are to be regarded as reports on ongoing studies and the authors will be pleased to receive comments.

The views expressed in Working Papers are solely the responsibility of the authors and should not to be interpreted as reflecting the views of the Executive Board of Sveriges Riksbank. 


\title{
The Discursive Dilemma in Monetary Policy*
}

\author{
Carl Andreas Claussen ${ }^{\dagger}$ and $\quad$ Øistein Røisland ${ }^{\ddagger}$ \\ Sveriges Riksbank Working Paper Series No. 240
}

April 20, 2010

\begin{abstract}
The discursive dilemma implies that the policy decision of a board of policymakers depends on whether the board reaches the decision by voting directly on policy (conclusion-based procedure), or by voting on the premises for the decision (premise-based procedure). We derive results showing when the discursive dilemma may occur, both in a general model and in a standard monetary policy model. When the board aggregates by majority voting, a discursive dilemma can occur if either (i) the relationship between the premise and the decision is nonmonotonic, or (ii) if the board members have different judgments on at least two of the premises. Normatively, a premise-based procedure tends to give better decisions when there is disagreement on parameters of the model.
\end{abstract}

${ }^{*}$ We thank Petra Geraats, Francisco Ruge-Murcia, Lars E.O. Svensson, Ulf Söderström and Andreas Westermark for useful comments and discussions. We also thank seminar participants at the EEA 2006 congress, 12th International Conference on Computing in Economics and Finance, the Eight International Meeting of the Society for Social Choice and Welfare, Norges Bank Research Workshop on MPCs (2007), and participants at seminars at Bank of England, the central bank of Netherland and Sveriges Riksbank for useful comments on earlier drafts. The views expressed herein are solely the responsibility of the authors and should not be interpreted as reflecting the views of the Executive Board of Sveriges Riksbank or Norges Bank.

${ }^{\dagger}$ Sveriges Riksbank. Email: carl-andreas.claussen@riksbank.se

${ }^{\ddagger}$ Norges Bank. Email: oistein.roisland@norges-bank.no 


\section{Introduction}

In most central banks, interest rate decisions are made by a group of people and not by a single policymaker. It is an empirical fact that the members of these groups often disagree on the appropriate monetary policy, also after having discussed and shared their information and assessments. Disagreement generally reflects different judgments on relevant inputs for the decision, such as the size of the output gap, the effect on demand by a change in the interest rate, the slope of the Phillips curve, etc. If members disagree, the group must find a way to aggregate the different judgments into one decision. The usual way to do this is to vote over the relevant policy alternatives, that is, a conclusion-based procedure (CBP). An alternative way would be to vote over the size or importance of the relevant inputs and let the decision follow from the aggregate judgments on these inputs. Denote this a premise-based procedure (PBP). However, as the following example illustrates, $\mathrm{CBP}$ and $\mathrm{PBP}$ may give different decisions.

Suppose a monetary policy board agrees to set the interest rate according to the classical Taylor rule, i.e., $r_{t}=r r_{t}^{*}+\pi^{*}+1.5\left(\pi_{t}-\pi^{*}\right)+0.5 y_{t}$, where $r_{t}$ is the nominal interest rate, $r r_{t}^{*}$ is the neutral real interest rate, $\pi^{*}$ is the desired rate of inflation (inflation target), $\pi_{t}$ is the rate of inflation, and $y_{t}$ is the output gap. The neutral real interest rate $r r_{t}^{*}$ and the output gap $y_{t}$ are not observable in practice, and the board members must judge their value. Suppose that $\pi_{t}$ can be perfectly observed, and consider for simplicity a situation where inflation is on target; $\pi_{t}=\pi^{*}=2$. Suppose that the board has 9 members with individual estimates as in Table 1 . If the board votes on

Table 1: Example of the discursive dilemma

\begin{tabular}{cccc}
\hline \hline & \multicolumn{2}{c}{ Inputs } & Interest rate \\
\hline & $r r_{t}^{*}$ & $y_{t}$ & $r_{t}$ \\
\hline Members 1 - 3 & 2.0 & 1.0 & 4.5 \\
Members 4 - 6 & 2.5 & 0.0 & 5.0 \\
Members 7 - 9 & 2.0 & 0.0 & 4.0 \\
\hline Majority & 2.0 & 0.0 & 4.5 \\
\hline \hline
\end{tabular}

the interest rate, the result will be the median interest rate, i.e., $r_{t}=4.5$. $^{1}$ However, the interest rate which is consistent with the median judgments on the inputs is $r_{t}=4.0$. Thus, if the board instead of voting directly on the interest rate, votes on the inputs and lets the decision follow by the agreed upon rule, there will be a different decision. The board therefore faces what is called a 'discursive dilemma' (Pettit, 2001).

In this paper, we analyze the relevance and normative implication of the discursive dilemma for monetary policy decisions. First, we build a simple

\footnotetext{
${ }^{1}$ We assume here pairwise majority voting and single-peaked preferences.
} 
but general model where a policy board aggregates quantitative judgments by majority voting. Based on this model we give a new characterization of under what conditions a discursive dilemma may arise and under what conditions it never arises. Second, we apply the characterization from the first step to a canonical macroeconomic model and give corollaries for when a discursive dilemma may and may not arise for monetary policy decisions. Finally, we investigate the normative question of which procedure - CBP versus PBP - that gives better monetary policy decisions. Compared to the existing litterature on the discursive dilemma (see overview in Section 2), our paper is, to our knowledge, the first that investigates which procedure is the better when groups aggregate quantitative judgments.

The discursive dilemma seems unrecognized among both monetary theorists and practitioners, and economists more generally. To our knowledge, the only discussion of this issue in the monetary policy literature is the brief discussion by Faust and Henderson (2004) on "multistage decisionmaking", which is equivalent to our premise-based decision procedure. Faust and Henderson (p.133) claim that "there is no theorem of public decisionmaking stating that the multistage decisionmaking approach is good for society". Our analysis confirms that it is not possible to derive a general theorem that says that one of the two decision procedures is always better. But because of this, and since the two procedures often give different results, it is important to investigate when and understand why one decision procedure is better than the other. Using a standard monetary policy model, we find that a premise-based procedure tends to give lower expected loss than a conclusion-based procedure when the members have different judgment (estimates) on parameters of the model. Only in some special cases, where the board members are overconfident about their parameter estimates, is the conclusion-based procedure better. Thus, unless the members are very overconfident, the premise-based procedure does better.

The paper is organized as follows. In the next section we give a brief overview of relevant literature. We derive the general characterization result in Section 3. In Section 4 we give the subsequent corollaries for when a discursive dilemma may and may not arise for monetary policy decisions. We analyse which procedure gives better decisions in Section 5. We discuss some central assumptions and institutional implications of our results in Section 6, and conclude by Section 7 .

\section{Literature}

The setting in this paper is somewhat parallel to a setting where a group of people aggregates binary judgments on interconnected propositions. In such situations an aggregation inconsistency akin to the aggregation inconsistency in the example of Table 1 may arise. To illustrate, suppose a committee 
agrees that a conclusion $C$ is true if and only if two premises $P_{1}$ and $P_{2}$ are true, i.e. $C \leftrightarrow\left(P_{1} \wedge P_{2}\right)$. Then there is a discursive dilemma if the members of a committee with three members have judgments as in Table 2: Voting directly on the conclusion gives "No", while voting on the premises gives "Yes" on the conclusion.

Table 2: Example of the discursive dilemma in the binary case

\begin{tabular}{cccc}
\hline \hline & $P_{1}$ & $P_{2}$ & $C$ \\
\hline Member 1 & Yes & No & No \\
Member 2 & No & Yes & No \\
Member 3 & Yes & Yes & Yes \\
\hline Majority & Yes & Yes & No \\
\hline \hline
\end{tabular}

This example applies to many situations. Consider for example an editorial board of a journal deciding through majority voting whether a submitted paper should be published, based on two necessary and sufficient conditions: $P_{1}$ : "The results are novel", and $P_{2}$ :"The results are important". Another example is a monetary policy board deciding whether to use quantitative easing in a situation where the overnight policy rate is close to zero. Suppose that they agree that two premises must be satisfied: $P_{1}$ :"The current monetary policy stance is not sufficient to bring the economy out of the recession", and $P_{2}$ :"Quantitative easing will be effective in stimulating aggregate spending". Both these examples can be captured by Table 2 and thus be subject to a discursive dilemma. Furthermore, it is easy to construct other examples with different connections between the propositions, ${ }^{2}$ and different types of aggregators. ${ }^{3}$ Recent research show that these examples illustrate a more general aggregation problem when aggregating judgments on propositions: If the propositions under consideration are interlinked, then there exist no non-dictatorial aggregator fullfilling some mild requirements that always aggregates consistent individual judgments on these propositions into consistent collective judgments on these propositions (i.e. a discursive dilemma cannot be "ruled out"). List and Puppe (2009) and List (2010) provide overviews of these results and the literature on judgment aggregation. Dietrich (2007) provides a generalized model of binary judgment aggregation.

The question of which procedure - CBP versus PBP - is better when aggregating judgments on propositions has been approached from two per-

\footnotetext{
${ }^{2}$ Suppose, for instance, that the members agree that conclusion $C$ is true if and only if at least one of the two premises $P_{1}$ and $P_{2}$ are true, i.e., $C \leftrightarrow\left(P_{1} \vee P_{2}\right)$. Change all "yes" in table 2 with a "no" and all "no" with a "yes", and a discursive dilemma will occur.

${ }^{3}$ Consider Table 2 and suppose, for instance, that there is a fourth member with the same judgements as Member 1 (or Member 2). Suppose the aggregator is the following: The aggregate judgement is the majority judgement if there is no tie. If there is a tie the aggregate judgment is "yes".
} 
spectives. Pettit (2001) and Chapman (2003) apply a procedural perspective and argue that decisions should be made for the right reasons, which, in their view, favors PBP. They argue that this is particularly important from the perspective of deliberative democracy, since a premise-based procedure "collectivises" the reasons underlying a given decision. The second perspective, suggested by Bovens and Rabinowicz (2003), is epistemic: The best procedure is the one that is most likely to give the correct decision, irrespective of the underlying reasons. From this perspective, it does not matter whether a decision is reached through wrong judgments on the premises, as long as the decision itself is correct. List (2005) considers both approaches, and his simulation results, where the group aggregates by majority voting, show that PBP tends to be better than CBP both from a procedural and epistemic perspective. Even if simulation results tend to favour the premise-based procedure, the research confirms Faust and Henderson's (2004) claim that "there is no theorem of public decisionmaking stating that the multistage decisionmaking approach is good for society", as it is possible to specify assumptions under which CBP performs better than PBP, at least from an epistemic perspective. However, the results from the literature are less relevant for the type of decisions Faust and Henderson had in mind, namely monetary policy decisions. Monetary policy decisions sometimes involve binary judgments, but quantitative judgments - judgments on the value of relevant variables - are much more prevalent. Compared to the judgment aggregation literature the important novelty of our current paper is that variables need not be binary, which makes the framework more relevant for economic decisions in general and monetary policy in particular.

Considering the aggregation of different interconnected variables is not new. A variety of aggregation problems has been proposed and solved in production theory, see Blackorby and Schworm (1984) for an overview. Rubinstein and Fishburn (1986) consider the problem of aggregating the entries in $n$ rows in an $n \times m$ matrix into a summary row, where every entry is an element in an algebraic field. They find that if the entries always form a hyperplane, then every consistent aggregator is an aggregator whereby the aggregate estimate of a variable is the (normalized) linear sum of the individual estimates. If the entries do not form a hyperplane, there is no consistent non-dictatorial aggregator. The situation we study in this paper is somewhat similar to the situation studied by Rubinstein and Fishburn. However, an important difference is that we assign one variable the role as a dependent variable ('decision-variable') and the other variables the role as independent variables ('premise-variables'). Furthermore, we have less strict domain restrictions.

The analysis in this paper is also related to Claussen and Røisland (2010), who consider a general social choice-theoretic model and give a generalisation of the discursive dilemma to quantitative judgments in the case when the individual preferences are strict. In the current paper we relax the as- 
sumption of strict preferences and give a generalization for weak preferences under majority voting (and averaging). In addition, we apply the model to a monetary policy setting and analyze which of the two alternative procedures that gives better decisions.

\section{The quantitative discursive dilemma under ma- jority voting}

The typical economic decision-making problem is to decide the level of a decision-variable, which may be non-binary and depend on a set of variables and parameters which may also be non-binary (often continuous), which we call inputs for the decision. The relationship between the decision-variable and the inputs is given by the reaction function

$$
r=R\left(x_{1}, x_{2}, \ldots, x_{m}\right),
$$

where $r$ is the decision-variable and $x_{1}, x_{2}, \ldots, x_{m}$ are the input-variables. The reaction function could be the result of optimization, or it could be a simple policy rule.

When the decisions are taken by a group and some inputs are not fully observable, the group members may not agree on the size of the inputs in the reaction function. Moreover, even if the reaction function is based on observable input variables, the group members may disagree on the specification of the reaction function. For example, if the general reaction function is linear of the form $r=B X$, where $X$ is the vector of input-variables and $B$ is the vector of coefficients, the members might agree on the values of $X$, but disagree on $B$. We will define a premise-variable as a variable or parameter in the reaction function on which the members may disagree. Thus, the elements in $X$ and $B$ can be premise-variables or not depending on whether the members may disagree on their sizes. With this definition of premise-variables, we let the relation between the decision-variable $r$ and the premise-variables $p_{1}, p_{2}, \ldots, p_{k}$ be denoted the dependence function

$$
r=D\left(p_{1}, \ldots, p_{k}\right) .
$$

The dependence function is thus derived from the reaction function, where the variables and parameters in the reaction function on which the group members may disagree, enter as arguments (premise-variables) in the dependence function. $k$ is the number of premise-variables. Parameters or variables which there are never disagreement about are captured by the functional form $D(\cdot)$. Since everything the members may disagree on is defined as premise-variables, they agree by construction on the $D(\cdot)$-function.

The $D(\cdot)$-function is just an analytical device which is useful for analyzing the discursive dilemma, and the assumption that all members agree 
on the dependence function is not a strong assumption. The existence of a dependence function only requires that there exists one property of the reaction function on which the members can agree. To fix ideas, consider the reaction function $r=R(\pi)=\alpha \pi$, where $\pi$ is underlying inflation and $\alpha$ is the coefficient on inflation. If the members of the board agree on the reaction function, but may have different estimates of underlying inflation, the dependence function is equal to the reaction function, i.e., $r=D(\pi)=\alpha \pi$. If the members instead can observe $\pi$, but may disagree on the coefficient $\alpha$, then $\alpha$ is the premise-variable and $\pi$ is the coefficient in the dependence function, i.e., $r=D(\alpha)=\pi \alpha{ }^{4}$ If the members may disagree on both the response coefficient and the level of underlying inflation, we have that $r=D(\alpha, \pi)=\alpha \pi$. Note that the dependence function now becomes multiplicative even if the underlying reaction function is linear. If one can specify a general form of the reaction function $R(\cdot)$ that encompasses all members' individual reaction functions, and if this function can be described by a finite set of parameters, it is always possible to specify a dependence function. Since the focus of the paper is on judgment aggregation, it is natural to focus on the dependence function instead of the reaction function, as the former specify the relationship between the decision and the potentially diverging individual judgments. With this definition of a dependence function, there is a discursive dilemma if the majority judgments on the premise-variables support another decision than the outcome of a majority vote on the decision, as illustrated by the example of Table 1 in the introduction.

We will now give a more general characterization of when there is a discursive dilemma. Consider a board with $n$ members, where $n>2$ and odd. The dependence function is given by (2) where each premise-variable can take values in a set $P_{j} \in \mathbb{R}$. The set $P_{j}$ has at least two elements and might be finite or infinite. Thus, premise-variables may be continuous or discrete variables, and the domain of the dependence function is $P_{1} \times \ldots \times P_{k}$. Let $p_{j, i}$ denote member $i$ 's estimate on (judgment of) premise-variable $j$, i.e. $p_{j, i} \in P_{j}$. Since each member agrees (by construction) on the dependence function, member $i$ 's preferred $r$ is given by

$$
r_{i}=D\left(p_{1, i}, p_{2, i}, \ldots, p_{k, i}\right) .
$$

An individual sequence (of estimates) $q_{i}$ is a vector with one estimate for each premise variable and one estimate for the decision variable such that (3) holds, i.e., $q_{i}=\left(p_{1, i}, \ldots, p_{k, i}, r_{i}\right)$. A profile (of individual sequences) $g=\left(q_{1}, \ldots, q_{n}\right)$ is an $n \times(k+1)$-touple with one sequence for each member.

For each variable, the committee aggregates the individual judgments

\footnotetext{
${ }^{4}$ The coefficient in the dependence function will then be time-varying, as $\pi$ is timevarying. However, the dependence function is defined over the individual judgments at a given point in time (i.e., the monetary policy meeting) and has thus a "cross-section" distribution.
} 
Table 3: Scheme of aggregation

\begin{tabular}{c|ccccccc} 
& $p_{1}$ & & $p_{j}$ & & $p_{k}$ & & $r$ \\
\hline 1 & $p_{1,1}$, & $\cdots$ & $p_{j, 1,}$, & $\cdots$, & $p_{k, 1}$ & $D(\cdot) \rightarrow$ & $r_{1}$ \\
$\vdots$ & $\vdots$ & & $\vdots$ & & $\vdots$ & & $\vdots$ \\
$i$ & $p_{1, i}$, & $\cdots$, & $p_{j, i}$, & $\cdots$, & $p_{k, i}$, & $D(\cdot) \rightarrow$ & $r_{i}$ \\
$\vdots$ & $\vdots$ & & $\vdots$ & & $\vdots$ & & $\vdots$ \\
$n$ & $p_{1, n}$, & $\cdots$, & $p_{j, n}$, & $\cdots$, & $p_{k, n}$ & $D(\cdot) \rightarrow$ & $r_{n}$ \\
& & & & & & & \\
& $A(\cdot)$ & & $A(\cdot)$ & & $A(\cdot)$ & & $A(\cdot)$ \\
& $\downarrow$ & & $\downarrow$ & & $\downarrow$ & & $\downarrow$ \\
& $p_{1}^{A}$, & $\cdots$ & $p_{j}^{A}$, & $\cdots$, & $p_{k}^{A}$ & $D(\cdot) \rightarrow$ & $r^{P}, r^{C}$
\end{tabular}

into the committee's aggregate judgment by some aggregator $A(\cdot)$ (e.g., the median or the mean of the individual estimates for each variable). Denote the aggregate estimates by $p_{j}^{A}, j=1, \ldots, k$ and $r^{A}$, i.e.

$$
\begin{aligned}
p_{j}^{A} & =A\left(p_{j, 1}, p_{j, 2}, \ldots, p_{j, n}\right), \quad j=1, \ldots, k \\
r^{A} & =A\left(r_{1}, r_{2}, \ldots, r_{n}\right) .
\end{aligned}
$$

We can now define PBP as

$$
r^{P}=D\left(p_{1}^{A}, p_{2}^{A}, \ldots, p_{k}^{A}\right),
$$

while CBP is defined as

$$
{ }^{C}=A\left(r_{1}, \ldots, r_{n}\right) .
$$

The aggregation problem is illustrated in Table 3. We then have the following definition of the discursive dilemma for non-binary judgments:

Definition 1 There is a discursive dilemma for profile $g=\left(p_{1,1}, \ldots, p_{k, 1}, r_{1}, \ldots, p_{1, n}, \ldots, p_{k, n}, r_{n}\right)$ if $r^{C} \neq r^{P}$.

We see that the existence of a discursive dilemma depends on both the dependence function $D(\cdot)$ and the aggregator $A(\cdot)$. We shall focus on $m a-$ jority voting, but discursive dilemmas may arise also with other aggregators. For example, if the group uses averaging as the aggregation method, it follows directly from Jensen's inequality that there is a discursive dilemma if the dependence function is non-linear, since $\operatorname{mean}\left(D\left(p_{1}, p_{2}, \ldots, p_{n}\right)\right)=$ $D\left(\right.$ mean $\left.\left(p_{1}, p_{2}, \ldots, p_{n}\right)\right)$ only if $D$ is linear and under some special non-linear functions. The reason why we focus on majority voting is that this is the most commonly used aggregation method among monetary policy boards in practice. Although majority voting is generally not the optimal aggregation 
method, it has the advantage that it is, under certain assumptions, robust to strategic behavior (Black 1948). ${ }^{5}$ This property, together with its simplicity, probably explains the popularity of majority voting. Linear aggregators like averaging on the other hand, are very vulnarable to strategic behavior and are rarely used in practice, at least by monetary policy boards. We shall discuss strategic behavior further in Section 6.1.

We assume that each member's 'preferences' over each variable are singlepeaked around the member's best estimate of the variable. ${ }^{6}$ Then the outcome of a pairwise majority vote over the alternative values for a variable is - by the median voter theorem - the median of the individual estimates for the variable. With the median as the aggregator we can have that $r^{C} \neq r^{P}$ even if $D$ is linear, as illustrated by the example in the introduction. However, if $D$ is linear, there must be more than one premise-variable in order to have a discursive dilemma under majority voting. In the case of only one premise-variable, i.e., $k=1$, there will never be a dilemma if $D$ is monotonic, since there is a one-to-one mapping from the premise-variable to the decision-decision variable. If $D$ is strictly non-monotonic, a discursive dilemma can exist even if $k=1$, see example in Figure 1. The following proposition summarizes this result:

Proposition 1 Suppose that, for each variable, the board aggregates over the individual estimates by a pairvise majority vote over the alternative estimates for the variable. Suppose that each member of the board has single peaked preferences over each of the variables. Then there exists a profile of individual estimates with a discursive dilemma if and only if

(i) there are two or more premise-variables, or

(ii) there is one premise-variable and the dependence function is strictly non-monotonic.

Proof. See Appendix (which also have a strict formal model of the aggregation problem).

The proposition is related to the characterization in Claussen and Røisland (2010), but the above proposition is derived under more general assumptions about the members' preferences over the alternatives for each

\footnotetext{
${ }^{5}$ There is a caveat to this; if MPC members are allowed to express non-single-peaked preferences, voting cycles may occure. Depending on how these cycles are resolved, there can be incentives for single members or groups of members to behave strategically, see e.g. Blin and Satterthwaite (1976) for a simple example.

${ }^{6}$ By 'preferences' over variable $j$ (or the policy variable) we mean a complete, transitive and weak order on $P_{j}$ (or a set $Y \subseteq \mathbb{R}$ of alternatives for $r$ ). The term 'preference' should not be taken literally. All we assume is that each member can, for any two distinct alternatives $x, z \in P_{j}$ (or $Y$ ), say that she weakly 'prefers' $x$ to $z$ (or $z$ to $x$ ). The definition does not say anything about why she 'prefers' $x$ to $z$. Member $i$ could, for instance, prefer $x$ to $z$ because she finds that $x$ gives her higher utility than $z$, she could prefer $x$ to $z$ because she believes that $x$ is closer to the true value of the variable than $z$ (it is a "better estimate"), or - if variable $j$ is a policy variable - she could prefer $x$ to $z$ because she finds that $x$ gives higher social welfare than $z$.
} 
variable, but less general assumptions about the aggregation method. Proposition 1 applies to any sort of collective economic decisions, not only collective monetary policy decisions. It applies, for example, to corporate boards deciding on investment projects based on judgments on costs and revenues, or committees of experts giving advice on the appropriate level of taxes.

Regarding the normative question of which procedure that gives better decisions, it is not possible to derive a general proposition. To investigate the relevance of the dilemma in practice and the normative question of which procedure that gives the better decisions, one has to apply a particular model. In the next section we investigate these issues within a standard New Keynesian monetary policy model.

\section{The discursive dilemma in monetary policy}

The model in Section 3 applies to any group making decisions based on quantitative judgments. In the rest of the paper, we apply the general model to monetary policy decisions, but the results have relevance also for other types of decisions. Since the groups making monetary policy decisions have different names in different countries, we will in the following use the generic term 'monetary policy committee' (MPC) for such groups. The policy instrument is the interest rate, which the MPC decides by majority voting. We abstract from strategic voting. As in Section 3, we assume that each MPC member's preferences over each variable is single-peaked around the member's best estimate of the variable, such that the median voter theorem applies. In Section 6, we discuss the assumption of majority voting and non-strategic voting.

An MPC meeting can be thought of as a two-stage process. In the first stage - the deliberation stage - the MPC members share their individual judgments and discuss relevant issues. In the second stage - the decision stage - the MPC decides on the interest rate. During the deliberation stage, the MPC members may adjust their judgments such that they converge to a common judgment, but they may not always reach full consensus. The focus of the paper is not on optimal information pooling or on why members may still disagree after the deliberation stage. We therefore assume that the MPC has been through the deliberation stage, but has not reached full consensus. And indeed, the minutes from the monetary policy meetings of the policy boards of various central banks reveal a great deal of disagreement. At the bank of England, for instance, there has been dissent at about 60 percent of the meetings. At the Bank of Japan there has been dissent at 50 percent of the meetings, and at the Swedish Riksbank at about 34 percent of the meetings. On the face of it, the degree of dissent appears smaller at the FOMC. Meade (2005) reports a dissent rate of 7.5. However, she finds that the FOMC's rates of disagreement are quite similar to dissent rates at the 
Bank of England if one looks at opinions expressed during the discussion of policy proposals.

Most existing theories on the information pooling role of MPCs do not deduct why members still disagree after the deliberation stage. However, Gerlach-Kristen (2008) models the deliberation stage and assumes that each member observes the other members' signals with an error, which explains why disagreement will persist also after optimal Bayesian updating. Other reasons for disagreement can be found in experimental evidence from cognitive psychology showing that people generally do not aggregate information in an unbiased manner. One reason for such a bias is overconfidence. Overconfidence has been found in many professions, ${ }^{7}$ and it would be surprising if it was not also present among monetary policymakers. We will come back to the implications of overconfidence for the choice of decision procedure below.

\subsection{The model}

We consider the canonical New Keynesian model

$$
\begin{gathered}
\pi_{t}=\beta E_{t} \pi_{t+1}+\kappa y_{t}+u_{t}, \\
y_{t}=E_{t} y_{t+1}-\alpha\left(r_{t}-E_{t} \pi_{t+1}\right)+v_{t},
\end{gathered}
$$

where $\pi_{t}$ is inflation, $y_{t}$ is the output gap, $r_{t}$ is the interest rate, $u_{t}$ is a "cost-push" shock, for example, stemming from stochastic variations in firms' market power, and $v_{t}$ is a "demand shock", which could be interpreted as stochastic variations in the natural rate of interest, where the long-run equilibrium real rate is for simplicity set to zero. The MPC's objectives are represented by a standard loss function

$$
L_{t}=\pi_{t}^{2}+\lambda y_{t}^{2},
$$

which might be interpreted as the mandate given to the central bank by the political authorities. The problem of the MPC is to set the interest rate so as to minimize the discounted sum of current and expected future losses, i.e., $E_{t} \sum_{h=0}^{\infty} \beta^{h} L_{t+h}$.

As a benchmark, consider first the case where the MPC members have identical judgments. This case is tantamount to the case with a single policymaker. We assume that the MPC follows a discretionary policy. Assuming commitment in stead of discretion would add history-dependence to the reaction function, but the nature of the discursive dilemma would not change. We therefore focus on discretion to keep the analysis as simple as possible.

\footnotetext{
${ }^{7}$ See Yates (1990) for a survey.
} 
The first-order condition of optimal policy under discretion is ${ }^{8}$

$$
\kappa \pi_{t}+\lambda y_{t}=0 .
$$

The first-order condition (9) can be interpreted as a 'target criterion' (Svensson (2003) and Woodford (2007). In section 5.2 we will discuss how commitment to a target criterion could support premise-based decisions. We will, however, assume here that the MPC does not commit to a target criterion, but votes on the instrument. We then need to derive from (9) the reaction function. Inserting the Phillips curve and the IS-curve into (9) and solving for the interest rate gives the reaction function

$$
\begin{aligned}
r_{t} & =R\left(E_{t} \pi_{t+1}, E_{t} y_{t+1}, v_{t}, u_{t}\right) \\
& =\frac{1}{\alpha}\left[\frac{\alpha\left(\kappa^{2}+\lambda\right)+\kappa \beta}{\left(\kappa^{2}+\lambda\right)} E_{t} \pi_{t+1}+E_{t} y_{t+1}+v_{t}+\frac{\kappa}{\kappa^{2}+\lambda} u_{t}\right] .
\end{aligned}
$$

With rational expectations, we know that the system (6), (7) and (10) satisfies the Blanchard-Kahn conditions for equilibrium determinacy, and a sufficient condition is that the coefficient on $E_{t} \pi_{t+1}$ is greater than one. Note that this coefficient is always greater than one, irrespective of the judgments on the parameters. Thus, even if the individual MPC members might have different preferred coefficients on expected inflation in their individual reaction functions, the Taylor principle will still always be satisfied, and a unique equilibrium will be established. To keep the reaction function as simple as possible, we assume that there is no persistence in the shocks, i.e., $E_{t} v_{t+1}=E_{t} u_{t+1}=0$, which implies that the unique equilibrium is characterized by $E_{t} \pi_{t+1}=E_{t} y_{t+1}=0$. We will therefore for simplicity disregard these terms in (10) and use the function

$$
r_{t}=\frac{1}{\alpha}\left[v_{t}+\frac{\kappa}{\kappa^{2}+\lambda} u_{t}\right]
$$

as our "reaction function", although (11) is actually a reduced-form solution and not a reaction function as (10). ${ }^{9}$ We will modify the reaction function slightly below in order to depart from certainty equivalence.

\footnotetext{
${ }^{8}$ Under commitment to the timeless perspective, the level of the output gap is replaced by the change in the output gap, see Clarida, Gali, and Gertler (1999).

${ }^{9} \mathrm{An}$ important difference between the reaction function (10) and the reduced-form solution (11) is that inserting (10) into the model (6) and (7) gives determinacy, while inserting (11) into the model gives indeterminacy, since the interest rate in (11) only responds to exogenous variables.
} 


\subsection{The discursive dilemma}

Based on equation (11), we see that disagreement about the interest rate can be due to disagreement about (i) preferences $(\lambda),{ }^{10}$ (ii) state-variables $\left(v_{t}\right.$ and $u_{t}$ ), or (iii) parameters $(\alpha$ and $\kappa)$. We shall discuss each in turn. Note that non-state-variables (jump-variables) like $\pi_{t}$ and $y_{t}$ are functions of both state-variables and parameters of the model. We may then decompose disagreement on jump-variables into disagreement on state-variables and/or parameters.

\subsubsection{Preferences}

Consider first the case where the MPC members may differ in their preferences, i.e., they have different $\lambda \mathrm{s}$ in their loss functions (8). Evidence of such preference heteregeneity in MPCs are found in Riboni and RugeMurcia (2008). Recent research derives model-based loss functions based on the utility of the representative household. $\lambda$ depends then on the deep parameters of the model. From this perspective, disagreement about deep parameters gives rise to disagreement about $\lambda$. Even if this approach ensures consistency between the model and the loss function, the relationship between $\lambda$ and the deep parameters in the model is likely to be less clear when considering MPC members' preferences and assessments in practice. Therefore, we adopt the traditional approach to the loss function, where $\lambda$ represents the policymaker's preferences, and disregard a potential relationship between the MPC members' preferred $\lambda \mathrm{s}$ and their estimates of the deep parameters of the model.

From the reaction function (11) we see that the dependence function $r_{t}=D(\lambda)$ is monotonic in $\lambda$. Thus, together with Proposition 1 we have the following result:

Corollary 1 There will never be a discursive dilemma if the MPC members disagree on $\lambda$ only.

Since there is no difference between $r^{C}$ and $r^{P}$ when the MPC members disagree on $\lambda$ only, the two procedures - PBP and CBP - are of course normatively equivalent in this case. However, we should add that this only holds when there are two variables in the loss function, and thus one relative weight. If there are more than two variables, and thus more than one relative weight, for example an additional term with interest rate smoothing, discursive dilemmas could occur.

\footnotetext{
${ }^{10}$ Note that 'preferences' here is used in a different meaning than in section 3 , where the term is defined in footnote 6 . $\lambda$ refers to preferences on the appropriate trade-off between inflation and output stabilization.
} 


\subsubsection{State-variables}

Suppose that the MPC members may disagree about the state-variables in the reaction function, i.e., on $v_{t}$ and/or $u_{t}$. Although it is common in the literature to assume that the state-variables are perfectly observable, this is not the case in practice. ${ }^{11}$ With potential disagreement about the shocks, the dependence function $r_{t}=D\left(v_{t}, u_{t}\right)$ is linear. With disagreement about the size of only one of the state-variables, we have from Proposition 1:

Corollary 2 There will never be a discursive dilemma if the MPC members disagree about only $v_{t}$ or $u_{t}$.

If the MPC members disagree on both $v_{t}$ and $u_{t}$, we have:

Corollary 3 A discursive dilemma can occur if the MPC members disagree about both $v_{t}$ and $u_{t}$.

\subsubsection{Parameters}

Suppose that the MPC members may disagree about the parameters in the model, that is, on $\alpha$, and $\kappa$ in (11), but agree on the state-variables. The various parameters enter the reaction function (11) differently, which gives rise to a different functional form of the dependence function depending on which parameter the MPC members disagree on. We consider each parameter separately.

Consider first disagreement on the interest rate elasticity, that is, the size of $\alpha$. We see from (11) that the dependence function $r=D(\alpha)$ becomes non-linear, but monotonic. Thus, together with Proposition 1 we have the following:

Corollary 4 There will never be a discursive dilemma if the MPC members disagree about $\alpha$ only.

Consider then the case where the MPC members disagree only about the slope of the Phillips curve, i.e., $\kappa$. Evidence of different individual judgments on $\kappa$ is found in Tillmann (2009), based on the data set on the FOMC members' individual forecasts provided by Romer (2009). With disagreement on $\kappa$, the dependence function $r=D(\kappa)$ becomes strictly non-monotonic (unless $\lambda=0$ ). Thus, Proposition 1 implies the following result:

Corollary 5 A discursive dilemma may occur if the MPC members disagree about $\kappa$ only, except in the special case with $\lambda=0$.

\footnotetext{
${ }^{11}$ Walsh (2007) assumes that the shocks are observed with noise, and he discusses the optimal degree of transparency when the central bank has private information about the shocks.
} 


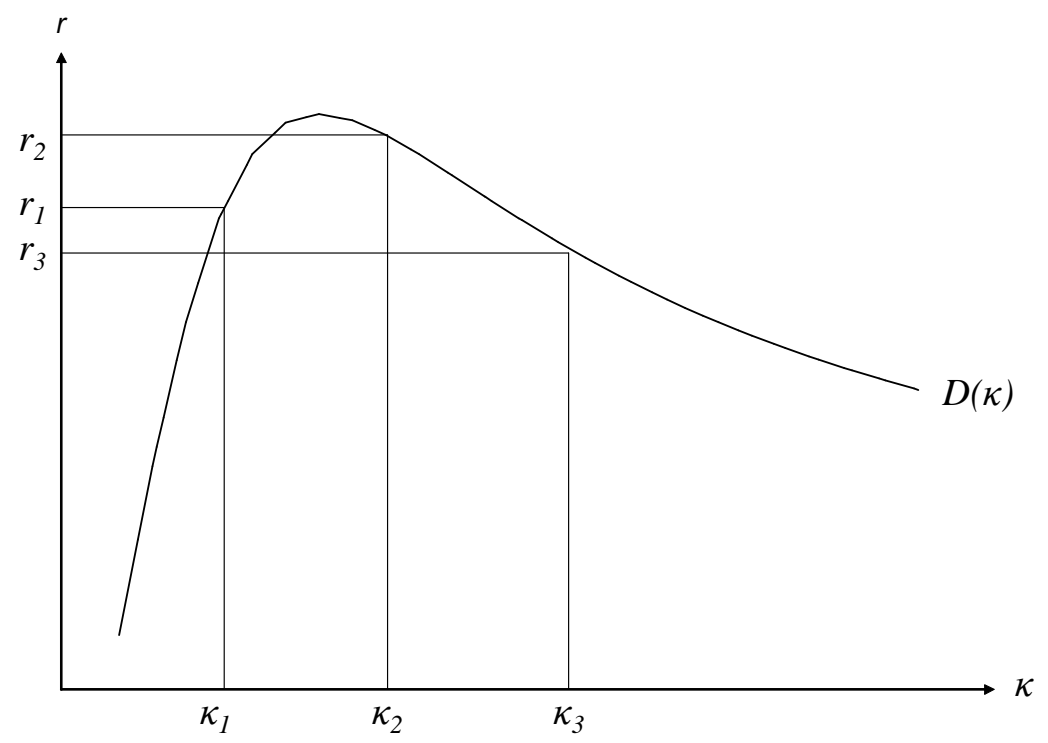

Figure 1: The discursive dilemma under disagreement on $\kappa$ (and $u_{t}>0$ ).

The corollary is illustrated in Figure 1, where there are three members of the MPC with estimates $\kappa_{1}, \kappa_{2}, \kappa_{3}$. The median judgment on the slope coefficient is $\kappa_{2}$, which implies the interest rate $r_{2}$, while the median judgment on the interest rate is $r_{1}$.

Notice also that since $D(\kappa)$ has only one local maximum (which is also global), we have that $r^{P} \geq r^{C}$, i.e, the interest rate responds more aggressively to cost-push shocks under PBP than under CBP. ${ }^{12}$ Thus, we have the following proposition:

Proposition 2 When there is disagreement on $\kappa$, and the discursive dilemma applies, CBP implies a more attenuated response to shocks than PBP.

Proof. See appendix.

Above we have implicitly assumed that the MPC members do not take uncertainty into account when making judgment about the appropriate interest rate. This is a reasonable assumption when there is additive uncertainty, since certainty equivalence holds in linear-quadratic models with additive uncertainty. However, when considering parameter uncertainty, which enters multiplicatively, certainty equivalence no longer holds. We now apply the more reasonable assumption that the individual MPC members consider

\footnotetext{
${ }^{12}$ With negative shocks, the case is symmetric, i.e., one minimum and $r^{P} \leq r^{C}$.
} 
their judgments uncertain and take that into account when judging the appropriate interest rate. The MPC members are thus assumed to minimize the loss function (8) conditional on their information and the uncertainty they attach to their estimates. Following the seminal work of Brainard (1967), taking parameter uncertainty into account gives the following generalization of the reaction function (10):

$$
\begin{aligned}
r_{t}= & R\left(E_{t} \pi_{t+1}, E_{t} y_{t+1}, v_{t}, u_{t}\right)=\frac{\left(\alpha^{2}+\sigma_{a}^{2}\right)\left(\kappa^{2}+\sigma_{k}^{2}+\lambda\right)+\alpha \kappa \beta}{\left(\alpha^{2}+\sigma_{\alpha}^{2}\right)\left(\kappa^{2}+\sigma_{k}^{2}+\lambda\right)} E_{t} \pi_{t+1} \\
& +\frac{\alpha}{\alpha^{2}+\sigma_{\alpha}^{2}}\left[E_{t} y_{t+1}+v_{t}+\frac{\kappa}{\kappa^{2}+\lambda+\sigma_{\kappa}^{2}} u_{t}\right] .
\end{aligned}
$$

The parameters $\alpha$ and $\kappa$ should now be interpreted as the estimates of the true, but unobservable, parameters, and $\sigma_{\alpha}^{2}$ and $\sigma_{\kappa}^{2}$ are the variances of the judgment error in the estimates of $\alpha$ and $\kappa$ respectively. Again, the reaction function implements a unique rational-expectations equilibrium characterized by $E_{t} \pi_{t+1}=E_{t} y_{t+1}=0$, and we can therefore focus on the reduced-form solution, which is given by

$$
r_{t}=\frac{\alpha}{\alpha^{2}+\sigma_{\alpha}^{2}}\left[v_{t}+\frac{\kappa}{\kappa^{2}+\lambda+\sigma_{\kappa}^{2}} u_{t}\right] \text {. }
$$

As shown by Brainard, this type of parameter uncertainty gives rise to a more cautious policy response to the shocks, although this is not a general result. ${ }^{13}$

The individuals may or may not have the correct perception of the degree of uncertainty. Let $\tilde{\sigma}_{j}^{2}$ denote the perceived variance of the judgment error of premise-variable $j$. Consider first the case where the MPC members have different judgments on $\alpha$, but take parameter uncertainty into account when forming their desired interest rates. We see that the dependence function $r_{t}=D(\alpha)$ implied by (13) is non-monotonic in the case where $\tilde{\sigma}_{\alpha}^{2}>0$, contrary to the case with no perceived parameter uncertainty. With perceived uncertainty about $\kappa$, the dependence function $D(\kappa)$ is still strictly non-monotonic. Thus, we may summarize the results under disagreement about $\alpha$ and $\kappa$ when MPC members take uncertainty into account as follows:

Corollary 6 If the MPC members take uncertainty into account, a discursive dilemma may occur if the MPC members disagree about $\alpha$ and/or $\kappa$.

Since the discursive dilemma applies under disagreement about both $\alpha$ and $\kappa$ when the MPC members take uncertainty into account, and the functional form of $D(\alpha)$ and $D(\kappa)$ is as in Figure 1, we have the following proposition (sse proof of Proposition 2 in Appendix):

\footnotetext{
${ }^{13}$ For example, Soderstrom (2002) showed that uncertainty about the coefficient on lagged inflation in the Phillips curve gives rise to a more aggressive policy.
} 
Proposition 3 When the MPC members have different estimates of $\alpha$ or $\kappa$ and consider their estimates uncertain, the discursive dilemma implies that $C B P$ gives a more attenuated response to shocks than PBP.

The more attenuated response under CBP comes in addition to the Brainard type policy attenuation that follows from parameter uncertainty. The difference between the two procedures in terms of the interest rate response to shocks has potential welfare implications, which we shall analyze in the next section.

\section{Normative analysis}

As discussed in Section 2, the social choice literature approaches the normative question of which procedure is better from two perspectives. From a procedural perspective, the decision should be made for the right reasons. From an epistemic perspective, the best procedure is the one that is most likely to give the correct decision, irrespective of the reasons. Within a binary choice model, it is meaningful to consider the probability of a "correct" decision as the normative criterion. For example, a defendant is either guilty or not guilty, and the jury's task is to make the correct decision regarding the defendant's guilt. With no-binary judgments like monetary policy decisions, the relevant normative criterion from an epistemic perspective could be the expected loss. We will apply such an epistemic perspective and use expected loss as the normative criterion when evaluating CBP and PBP, without paying attention to which of the procedures that gives the best aggregate judgments on the premise-variables.

To compute the loss, we utilize the determinacy property of optimal policy, which in this model implies that $E_{t} \pi_{t+1}=E_{t} y_{t+1}=0$. We can then write the solutions for $y_{t}$ and $\pi_{t}$ as

$$
\begin{aligned}
y_{t} & =-\alpha r_{t}+v_{t} \\
\pi_{t} & =\kappa y_{t}+u_{t}=-\kappa \alpha r_{t}+\kappa v_{t}+u_{t},
\end{aligned}
$$

where $r_{t}$ is given by (13). Since we assume that the policymakers follow a time-consistent policy (discretion) and there is no extrinsic or intrinsic persistence in the model, it suffices to consider the current-period loss and disregard expected future losses. We can then write the reduced-form loss as

$$
L_{t}=\left(\kappa\left(-\alpha r_{t}^{P / C}+v_{t}\right)+u_{t}\right)^{2}+\lambda\left(-\alpha r_{t}^{P / C}+v_{t}\right)^{2},
$$

where $r_{t}^{P / C}$ denotes the reduced-form solution of the interest rate under PBP and CBP, as defined in equations (4) and (5), respectively. Since the distribution of the median in small samples does not have a tractable analytical solution, we evaluate the expected loss using Monte Carlo simulations. In 
the simulations we use the following assumptions.

1. The individual MPC members' judgments (estimates) of premise-variable $p_{j}$ are given by

$$
p_{j, i}=p_{j}+z_{j, i} . \quad j=1, \ldots k, \quad i=1, \ldots n,
$$

where $p_{j}$ is the true, but unobservable, value of premise-variable $j$, and $z_{j, i}$ is an i.i.d. judgment error. For state-variables, we assume that the judgment errors are normally distributed, while for parameters we assume that they have a gamma distribution in order to restrict the judgments on $\alpha$ and $\kappa$ to be non-negative. The members are equally competent, measured by $\sigma_{j}^{2}$, and our assumptions imply that the individual judgment errors $z_{j, i}$ are uncorrelated. One may interpret this assumption either as the case with no deliberations, or as a case in which the members do not take the other members' judgments into account when forming their posterior judgments after the deliberation round. ${ }^{14}$

2. The judgments of the $n$ members are drawn 100000 times. Since their judgments are unbiased, we focus on a given realization of the premise-variables. The true parameter values of the model is set to $\alpha=1, \kappa=0.125$ and $\lambda=0.021$, where the values are taken from Galí (2008, chapter. 3).

3. For each draw, the loss under CBP and PBP are computed, and the average loss of the 100000 draws are computed and used to compare the two procedures.

Since the normative question is only relevant when $\mathrm{CBP}$ and $\mathrm{PBP}$ give different decisions, we will only consider the situations where the discursive dilemma may occur. We will therefore consider the cases of (i) disagreement on $u_{t}$ and $v_{t}$, (ii) disagreement on $\alpha$, and (iii) disagreement on $\kappa$.

\subsection{Disagreement on $u_{t}$ and $v_{t}$}

Consider first disagreement on $u_{t}$ and $v_{t}$. By comparing the average loss for all the draws, we find - not surprisingly - that they are on average equal for CBP and PBP. In other words, even if the two procedures tend to give different interest rate decisions for actual realizations of judgments, $\mathrm{CBP}$ and PBP yield the same expected loss. ${ }^{15}$ Although this result is not

\footnotetext{
${ }^{14}$ This is arguably an extreme assumption, but allowing for information sharing, which would result in correlated judgment errors, will not affect the qualitative results. The crucial assumption is that there will be some disagreement even after the deliberation round.

${ }^{15}$ Our simulations show that there will be a discursive dilemma in more than two thirds of the meetings.
} 
surprising, as it is somewhat related to the certainty equivalence property of additive uncertainty in linear-quadratic models, the result still consitutes an important benchmark.

\subsection{Disagreement on $\alpha$}

Consider then disagreement about $\alpha$. Since certainty equivalence does not hold in this case, we assume that the MPC members take uncertainty into account. However, as argued above, it is not obvious what to assume about the MPC members' perception of the degree of uncertainty. As we will show below, the normative results depend on the MPC members' perception of the uncertainty in their estimates. We have from (13) that $u_{t}$ and $v_{t}$ enter the reaction function equivalently, and with no loss of generality of the results, we set $v_{t}=0$ and $u_{t}=1$. Figure 2 displays the expected loss under CBP and PBP as a function of how the members perceive the degree of uncertainty. We see that CBP is better when the perceived uncertainty is low, while PBP is better when the perceived uncertainty is relatively high. CBP gives better decisions when the MPC members are overconfident, since CBP gives a more attenuated policy response than PBP, which counteracts the excessive aggressiveness due to overconfidence. However, for an "optimal" degree of perceived uncertainty, defined as the perception that gives the minimum loss, PBP outperforms CBP. Only under extreme overconfidence, that is, for $\tilde{\sigma}_{\alpha}=0$, the two procedures give the same expected loss. The reason is that there is no discursive dilemma in this case, since the dependence function becomes monotonic when $\tilde{\sigma}_{\alpha}=0$. Note that the results on $\alpha$ carry over to disagreement about $\kappa$ in the special case where $\lambda=0$.

\subsection{Disagreement on $\kappa$}

Consider then disagreement about $\kappa$ in the general case where $\lambda>0$. Unless $\lambda$ is very small, in which the same qualitative picture as in Figure 2 prevails, the performance of the two procedures becomes as illustrated in Figure 3. We see that PBP performs better than CBP for any degree of perceived uncertainty. The reason is that a positive $\lambda$ cuts off the left part of Figure 2 , such that only the right part of the curve applies. This can be seen from equation (13), where $\tilde{\sigma}_{k}^{2}$ and $\lambda$ enter the dependence function similarly. Having a positive $\lambda$ is thus mathematically equivalent to having a higher $\tilde{\sigma}_{\kappa}^{2}$. Thus, increasing $\lambda$ from 0 gradually cuts the left part of the Figure 2, and the range of $\tilde{\sigma}_{\kappa}^{2}$ in which CBP performs better than PBP diminishes.

Table 4 summarizes our finding for the three cases. Our interpretation of the overall result favoring premise-based decisions, is that it is better to aggregate judgments directly on the uncertain variable (or parameter) than to transform the judgments into a decision-variable - the interest rate - and do the aggregation on the transformed variable. The dependence function 


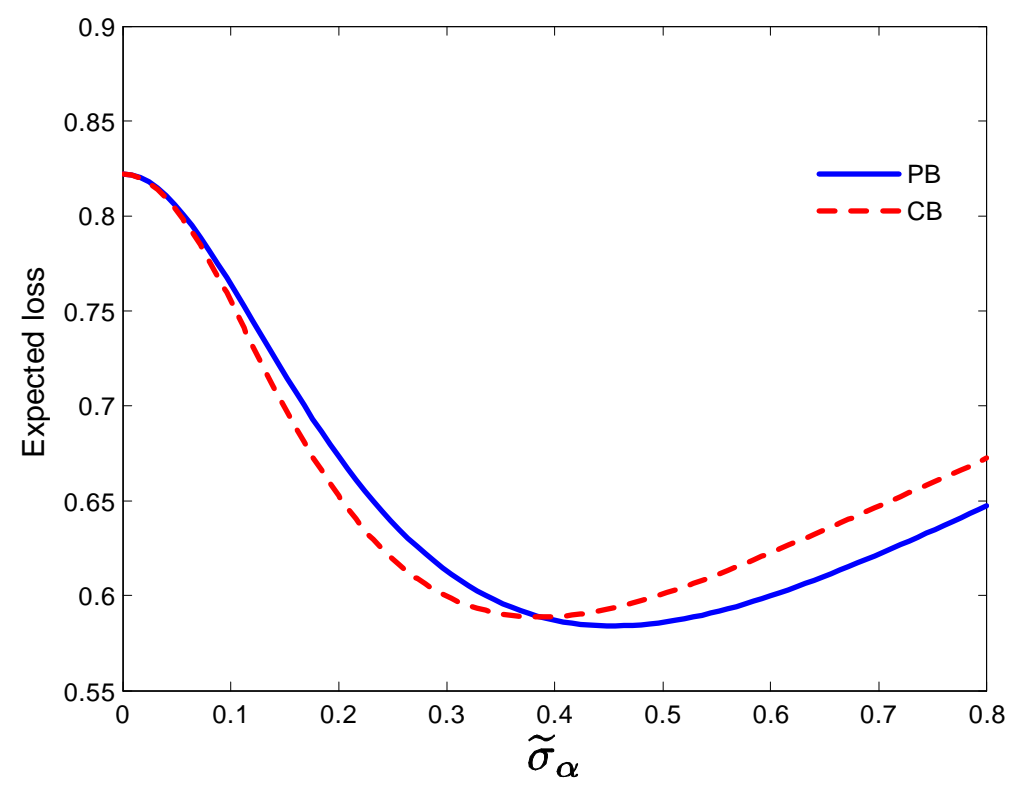

Figure 2: Expected loss under $\mathrm{PBP}$ and $\mathrm{CBP}$ as a function of perceived uncertainty of the judgment on $\alpha$.

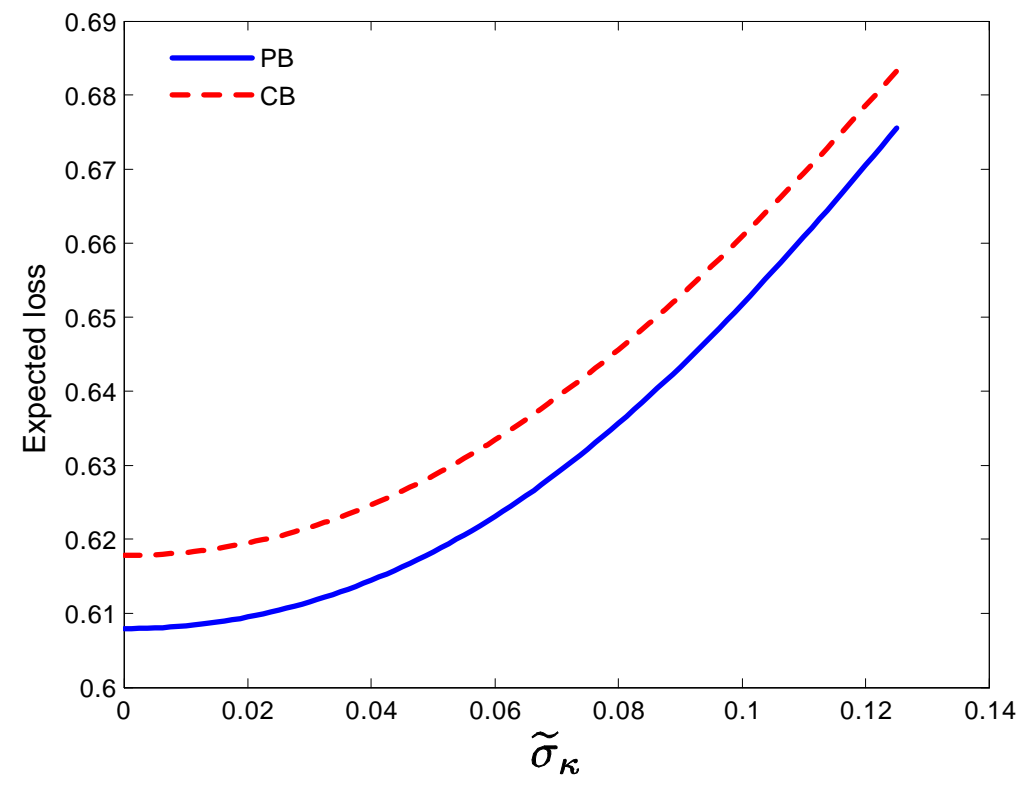

Figure 3: Expected loss under $\mathrm{PBP}$ and $\mathrm{CBP}$ as a function of perceived uncertainty in the judgment on $\kappa$. 
$D(p)$ that transforms the judgments on the premise-variables to the judgment on the interest rate, is derived from an optimal reaction function, but it is nothing that ensures that aggregating judgments on the transformed variable $D(p)$ gives a better pooling of information than aggregating judgments on $p$ and then use $D(p)$.

Table 4: Which decision-making procedure is better?

\begin{tabular}{lcl}
\hline \hline & Premise-variables & PBP vs CBP \\
\hline Case 1 & $v_{t}, u_{t}$ & $E L^{P}=E L^{C}$ \\
& $\alpha$ & $E L^{P}>E L^{C}$ if members are overconfident (low $\left.\tilde{\sigma}_{\alpha}\right)$ \\
Case 2 & $\alpha$ & $E L^{P}<E L^{C}$ if members are "underconfident" (high $\left.\tilde{\sigma}_{\alpha}\right)$ \\
Case 3 & $\kappa$ & $E L^{P}<E L^{C}$ \\
\hline \hline
\end{tabular}

\section{Discussion}

\subsection{Assumptions}

We have assumed that the MPC aggregates judgments by majority voting. We use this aggregator for three reasons. First, majority voting is widely used among MPCs in practice. ${ }^{16}$ Second, in theoretical models of collective decision-making, majority voting (and single peaked preferences) is typically assumed to be the aggregation method. Third, we want to relate our work to the existing literature on binary judgment aggregation and introduce a generalization of Pettit's (2001) binary discursive dilemma to non-binary quantitative judgments.

Majority voting is, however, not generally the optimal aggregation method. For example, in our model, where the MPC members are equally competent, averaging is a better aggregation method than majority voting, measured by the expected squared collective judgment error. However, averaging is not used by MPCs in practice. One reason could be that averaging is vulnerable to strategic behavior. ${ }^{17}$ We discuss majority voting and strategic behaviour below.

Even if majority voting often is the formal aggregation procedure in MPCs, for some central banks an agenda-setting model may give a more realistic description of the actual decision procedure. In such models, there is a cost of voting against the chairman, and in equilibrium the chairman will

\footnotetext{
${ }^{16}$ However, some MPCs, like the Governing Council of the ECB, claim that their decisions are consensus decisions. Nevertheless, it is hard to believe that policymakers in consensus-seeking central banks always agree, and probably also these committees will have to perform a vote, explicit or implicit, in the cases when members cannot agree.

${ }^{17}$ Under averaging, one member has unlimited power to influence the aggregate decision by reporting a false judgment. Thus, if more than one member acts strategically, there will not exist any Nash equilibrium under averaging.
} 
adjust his interest rate proposal such that he will never be outvoted, see. e.g., Riboni and Ruge-Murcia (2010). The agenda-setting models may, however, be considered as majority voting models with some additional restrictions on the voting structure or the utility functions, and the nature of the discursive dilemma will remain.

We have also (implicitly) assumed that the MPC uses the same aggregation method (majority voting) on all variables. However, if we allow for different aggregation methods on different variables, we open for discursive dilemmas also when the dependence function is strictly monotonic and there is only one premise-variable. Thus, our assumption of the same aggregation method on all variables bias the results towards less discursive dilemma situations, not more.

We have assumed that the MPC members report their true judgments. Although this assumption is a useful benchmark and a natural starting point for analyzing the difference between CBP and PBP, the assumption is not innocent. As mentioned in Section 3.1, majority voting is under certain assumptions robust to strategic behavior, since when preferences are singlepeaked, the outcome (median) is a Nash equilibrium. However, this result only applies to the one-dimensional case. We have assumed that the MPC members have 'preferences' on alternative values of the premise-variables, where 'preferences' here means ratings on how close to the truth a member judges the alternative values for a given premise-variable are. Therefore, while $\mathrm{CBP}$ makes the decision one-dimensional, since the MPC only decides on the interest rate, PBP breaks the one-dimensionality and opens up for strategic voting. The (lack of) strategy-proofness of PBP is considered by Dietrich and List (2007) in the binary judgment aggregation model. They find that PBP is only strategy-proof (i.e., not manipulable by strategic voting) for "reason-oriented" individuals, whereas PBP is not strategyproof for "outcome-oriented" individuals, in which case the outcome under PBP becomes identical to the outcome under CBP. The distinction between "reason-oriented" and "outcome-oriented" individuals is closely related to the distinction between a procedural and an epistemic perspective on decision-making mentioned in Section 2. The lack of stragey-proofness of PBP also applies to our model with quantitative judgments. If each MPC member is "outcome-oriented" and aims to achieve an interest rate decision that is as close as possible to his preferred interest rate, they have an incentive under PBP to report a false judgment on the premise-variable(s). To see how, consider member 1's judgment on $\kappa$ in Figure 1. Under PBP, the interest rate under truthfulness would be $r_{2}$. If member 1 instead reported a judgment on $\kappa$ which lies between $\kappa_{2}$ and $\kappa_{3}$, member 1 would become the median voter and dictate $r$. The other members will then not have any incentives to deviate, we have a Nash equilibrium, and PBP would yield the same result as CBP.

Although PBP may not be strategy-proof for "outcome-oriented" MPC 
members, we will in the next section discuss how various institutional settings may support premise-based decisions and thereby make strategic voting more conspicuous.

\subsection{Implications for institutional design and communication}

The above results suggest that the choice of decision-procedure matters, in particular when the MPC members disagree on parameters. Except in the case of overconfidence regarding the quality of individual judgments, PBP gives on average better decisions than CBP. This result has institutional implications, since it gives a case for designing institutions that support premise-based decisionmaking. In practice, MPCs seem to spend a considerable amount of time discussing important premises for the interest rate decision. Whether the interest rate decisions are characterized by PBP or CBP depends on (i) whether the judgments on these premises are aggregated to a common judgment (e.g., through voting) and (ii) whether the individual MPC members vote conditional on the aggregate judgments on the premises or conditional on their own individual judgments. The answer probably depends on the type of committee, in particular whether the committee is 'individualistic' or 'collegial'. ${ }^{18}$

The main inputs to policy decisions are the forecasts of inflation and economic activity. In some central banks, the MPC members take the staff forecasts as inputs, but do not take ownership of them. The Federeal Reserve System is an example of this. The members of the Federal Reserve Open Market Committee (FOMC) receive forecasts from the staff, but form their own individual forecasts based on their individual views on appropriate monetary policy. Even if the premises are discussed, it is likely that the FOMC members base their votes on their individual forecasts. Thus, the institutional setup and practice at the Federal Reserve System support conclusion-based decisionmaking.

In other central banks, like the Bank of England, the forecasts are owned by the MPC. The Bank of England's forecasts are said to represent the MPC's "best collective judgment", even if it is not clear exactly how the MPC decides on the forecasts. When the MPC owns the forecasts published in inflation reports or similar reports, the MPC members are more likely to let their votes be based on the forecast. Another device that can support premise-based decisionmaking is to have a "core" forecasting model, which represents the MPC's views on the economy. Then, different judgments on the importance of various economic mechanisms can be aggregated and reflected in the model.

One may conjecture that central banks with MPC-owned forecasts and MPC-owned core models to a larger degree conduct premise-based deci-

\footnotetext{
${ }^{18}$ See Blinder (2007) for a description of different types of committees.
} 
sions. However, this may not generally be the case, as other institutional settings can counteract PBP. For example, even if the MPC of the Bank of England owns the Inflation Report and the core model, the MPC members are individually accountable for their interest rate votes. This implies that each member's interest rate vote should be based on his/her own judgments on the premise-variables and not on the MPC's "best collective judgment" in cases where these judgments differ. Thus, individual accountability for the interest rate vote supports CBP, as opposed to PBP. However, it is in principle possible to relocate the individual accountability, such that the MPC members are held individually accountable for their judgments on the premise-variables instead of the interest rate. This would arguably be more consistent with MPC ownership of the inflation report and the core forecasting model.

Central banks would generally strive to achieve consistency between the decisions and the forecasts. However, the combination of individual accountability on interest rate votes, which implies CBP, and MPC-owned forecasts, as in the Bank of England case, gives rise to a challenge in terms of consistent communication. This challenge was identified and discussed by Donald Kohn, who was asked by the Bank of England to assess the transparency of the policymaking process at the MPC ${ }^{19}$ :

"To achieve at least rough alignment between policy and the forecast, whatever is published should reflect the "center of gravity" of the Committee that made itself felt in the most recent policy decision. However, determining and presenting a view that would explain actions and shape expectations constructively is difficult in the context of a Committee, especially one with emphasis on individual accountability."

If decisions are made by CBP, as in the Bank of England, the discursive dilemma implies that there may be inconsistency between the decision and the forecasts if the forecasts reflect the "center of gravity" of the MPC. The only way to ensure consistency under CBP is to publish the forecasts that are consistent with the forecasts belonging to the median voter on the interest rate. However, as our analysis of the discursive dilemma shows, the forecasts (that is, the judgments on the premises-variables) of the median voter on the interest rate may be quite different from the median judgments on the premises. Thus, if interest rate decisions are made by CBP, the MPC could either choose to present the median judgments on the premises, which might result in inconsistency between the decision and the forecasts, or to present the forecasts belonging to the median voter on the interest rate, which might not reflect the "center of gravity" of the MPC. A third option under CBP is to do like the FOMC, namely to present the forecasts of all MPC members instead of a single aggregate forecast. Potential inconsistencies between the decision and the forecasts are, however, always avoided if the MPC uses

\footnotetext{
${ }^{19}$ The 'Kohn report', Kohn (2001).
} 
PBP. Then, the decision follows directly from the aggregate judgments on the premises (forecasts).

One institutional obstacle to PBP is that it is difficult for an MPC to decide on a principle for the interest rate setting that gives rise to a dependence function on which each MPC member agrees. Full PBP implies that the interest rate decision follows from the dependence function, so that the MPC only needs to focus on the premise-variables. If the MPC decides to let the interest rate be dictated by an interest rate rule, where they vote on the coefficients in the rule, one could achieve PBP. However, for reasons put forward by Svensson (2003) and others, central banks are reluctant to commit to a specific interest rate rule. Woodford (2010) has suggested that central banks should instead specify a "target criterion" which determines monetary policy. One specification of such a criterion is

$$
\pi_{t}+\varphi\left(y_{t}-y_{t-1}\right)=0 .
$$

This target criterion corresponds to the first-order condition for optimal policy under commitment in a timeless perspective given the simple New Keynesian model presented in Section 4. Woodford suggests, however, that this criterion could provide a reasonably favorable outcome in more complex models, even if the first-order conditions in such models are less simple than (18). The MPC could vote on $\varphi$ and on the state-variables and parameters determining inflation and the output gap. The interest rate decision will then follow from the model and the target criterion, and the MPC can decide on the premise-variables instead of the interest rate. Generally, the research on monetary policy design has emphasized the importance of managing private sector expectations by committing to a specific reaction pattern. In order to make the reaction pattern credible, the central bank must be transparent about this pattern. Even if this literature does not focus on the collective nature of monetary policy decisions, it is hard to see how an MPC can commit to a certain reaction pattern without reaching a collective decision on this reaction pattern. Thus, we find that the recent research on monetary policy has clear focus on deciding on the premises for policy decisions.

It is, however, possible to implement $\mathrm{PBP}$ without having to reach a collective decision on the reaction pattern represented by a policy rule or target criterion, and we will here propose an alternative procedure. The procedure can be described as follows: 1) The MPC decides on a core model ${ }^{20}$ 2) The MPC decides on the inputs to the model (state-variables and parameters). 3) The staff produces a menu of forecasts based on 1) and 2), but with alternative weights $\lambda$ on output stability relative to price stability. 4) The MPC

\footnotetext{
${ }^{20}$ This may not always be feasible, for example if each member believes in different type of models and are not able to rank the alternative models. In practice, however, we do observe that many central banks have MPC-owned core models.
} 
votes on the alternative forecast scenarios conditioned on the different $\lambda$ s. 5) The winning conditional forecast scenario determines a unique interest rate (path).

With this procedure, the judgments are aggregated in a step-by-step fashion consistent with how the forecasts are built. By voting on alternative conditional forecasts, which differ only due to monetary policy, the MPC members will in effect vote on $\lambda$ even if this is done indirectly. Most MPC members, except perhaps academics with background in monetary theory, would probably find it more natural to express preferences by voting on alternative conditional forecasts than by voting on a parameter like $\lambda$.

This procedure is somewhat similar to Svensson's (2010) proposal on how monetary policy should be evaluated and decided upon. Svensson suggests that a set of efficient forecasts should be constructed, where 'efficient' means that it should not be possible to stabilize inflation or output better without stabilizing the other less well (in terms of the discunted sum of expected square inflation and output gaps). The set of efficient forecasts, from which the policymakers should choose, reflects different $\lambda$ s. Although Svensson does not discuss premise-based versus conclusion-based decision-making, his proposed decision procedure is in our view only consistent with a premisebased procedure. The reason is that if the MPC members should choose from a menu of efficient forecasts, representing different $\lambda \mathrm{s}$, each member must accept the alternative forecasts as efficient. This requires that prior to the provision of efficient forecasts, the MPC must have decided on a model from which the forecasts are derived and judgmental inputs to the model.

One might argue that in those central banks where the MPC decides not only on the current interest rate, but on the whole interest rate path, a premise-based procedure as the one suggested above is even more advantageous. When having decided on the model, the MPC could vote on the alternatives interest rate paths directly. If instead decisions are conclusionbased and there is disagreement about models or parameters, it would be difficult for an MPC to decide on a whole interest rate path without having to vote on each point on the interest rate path, which would be a cumbersome procedure.

\section{Conclusion}

In this paper, we have analyzed the relevance of the discursive dilemma for monetary policy decisions in MPCs. We have shown that under majority voting, the existence of the dilemma can only be excluded in the case where the MPC members only disagree on one premise-variable and when the relationship between this premise-variable and the decision is monotonic. Furthermore, we find that when the MPC members disagree on the parameters, a premise-based procedure tends to give lower expected loss than a 
conclusion-based procedure. The reason is that the functional form of the dependence function implies that conclusion-based decisions tend to give too weak policy responses to shocks. Only in the case where the MPC members are overconfident, and thus do not take parameter uncertainty sufficiently into account, can a conclusion-based procedure be a second-best solution that counteracts the negative effects of overconfidence. In addition, we have shown that the discursive dilemma represents a challenge to consistent communication. If the MPC uses a conclusion-based procedure and votes on the interest rate, the aggregate judgments represented by the economic forecasts published by the central bank are often inconsistent with the interest rate decision. Consistency between the interest rate decision and the published forecasts will, however, always be achieved with a premise-based procedure. The results in our analysis thus favor premise-based decisions, and the results have implications for how central banks (and other organizations) should organize the decision process. The results in this paper should, however, be regarded as a first step towards a better understanding of the properties of alternative decision-making procedures in committees. As postulated by Faust and Henderson (2004), and confirmed in our analysis, it is not possible to derive general results saying that one decision procedure always dominate the others normatively.

The underlying reason for why MPC members have different judgments is uncertainty. The type of disagreement we have analyzed is related to the type of uncertainty considered by Brainard (1967). There has been a huge literature on uncertainty and robustness since Brainard's seminal paper, and future work on judgment aggregation in monetary policy could find inspiration from this literature. For example, one strand of the literature on monetary policy under uncertainty considers robust policy rules when there is uncertainty about the true model. In line with this, one could analyze the robustness of the alternative decision procedures when the majority of the MPC may base their interest rate votes on the wrong model. Furthermore, if the MPC members believe in different kind of models, or have different "decision heuristics" (Blinder (2007)), it might be the case that premisebased decisionmaking is not possible. Faust and Henderson (2004) seem to have such a case in mind when arguing against multi-stage decisionsmaking. Monetary policy decisions are, however, complex decisions, and it might well be the case that an appropriate decision framework is to use a premise-based procedure at some stages of the process, and a conclusion-based procedure on other stages where it is not possible, or simply not practical, to use a premise-based procedure. In any case, it is important to be aware of the possible existence of the discursive dilemma in collective economic decisions in general, and monetary policy decisions in particular. 


\section{Appendix:}

\section{Proof of Proposition 1}

For the poof we need some auxiliary terminology and more precise definitions.

The decision variable can take values in a non-empty set $Y \subseteq \mathbb{R}$. This set has at least two elements and might be finite or infinite. Examples are $Y=\mathbb{R}^{+}$(the decison variable is continuous but with a zero lower boundrestriction), $Y=\{0.25,0.50, \ldots\}$ (the decision variable is discrete with a zero lower bound), and $Y=\{5.0,5.50\}$ (there are only two alternative values of the policy variable). Thus,

$$
D: P_{1} \times \ldots \times P_{k} \rightarrow Y .
$$

We assume that the dependence function is surjective. ${ }^{21}$

An estimate is an element in $P_{j}$ or $Y$. Estimates will be denoted by small letters. Estimates of premise-variables will be subindexed, i.e. $x_{j}, z_{j}$ are two estimates in $P_{j}$, and $x_{k}, z_{k}$ are two estimates in $P_{k}$, and so on. A premisevector, denoted $\boldsymbol{x}$, is a vector of estimates with one estimate for each of the $k$ premise-variables, i.e. $\boldsymbol{x}=\left(x_{1}, \ldots, x_{k}\right) \in P_{1} \times \ldots \times P_{k}$. A sequence, denoted $q$, consists of a premisevector $\boldsymbol{x}$ and an estimate of the conclusion $y$. We say that the sequence $q=(\boldsymbol{x}, y)$ respects the dependence function if $D(\boldsymbol{x})=y$. Let $\mathcal{X} \subseteq P_{1} \times \ldots \times P_{k} \times Y$ be the set of sequences that respects the dependence function. A profile individual estimates, denoted $g \in \mathcal{X}^{n}$, is an $(k+1) n$-tuple with one sequence for each member. For any profile $g \in \mathcal{X}^{n}$, denote the vector of median estimates of the premises $\boldsymbol{x}_{m(g)}$ and the median estimate of the decision variable $y_{m(g)}$. There is a discursive dilemma for profile $g$ if $D\left(\boldsymbol{x}_{m(g)}\right) \neq y_{m(g)}$.

\section{Proof}

Put $k=1$. If $D$ is weakly monotonic, it follows from $g \in \mathcal{X}^{n}$ (individual sequences respect $D)$ that $D\left(\boldsymbol{x}_{m(g)}\right)=y_{m(g)}$ for all $g \in \mathcal{X}^{n}$. If $D$ is (strictly) non-monotonic, $\left|P_{1}\right|>2$. If $\left|P_{1}\right|>2$ and $D$ is (strictly) non-monotonic it is, for any $n$, straight forward to make an example where $D\left(\boldsymbol{x}_{m(g)}\right) \neq y_{m(g)}$ and $g \in \mathcal{X}^{n}$.

Put $k>1$. Say that two premise vectors $\boldsymbol{x}^{\prime}$ and $\boldsymbol{x}^{\prime \prime}$ are distinct if $\boldsymbol{x}^{\prime} \neq \boldsymbol{x}^{\prime \prime}$. Say that two premise vectors $\boldsymbol{x}^{\prime}=\left(x_{1}, \ldots, x_{k}\right)$ and $\boldsymbol{x}^{\prime \prime}=\left(z_{1}, \ldots, z_{k}\right)$ are strictly distinct if for all $j \in\{1, \ldots, k\}, x_{j} \neq z_{j}$. As $\left|P_{j}\right|>1$ for $j=1, \ldots, k$ there are (always) four sequences, $q^{\prime}=\left(\boldsymbol{x}^{\prime}, y^{\prime}\right), q^{\prime \prime}=\left(\boldsymbol{x}^{\prime \prime}, y^{\prime \prime}\right), q^{*}=\left(\boldsymbol{x}^{*}, y^{*}\right)$,

\footnotetext{
${ }^{21} \mathrm{~A}$ function $D$ is said to be surjective or onto, if its values span its whole codomain; that is, for every $y \in Y$, there is at least one vector $\left(x_{1}, . ., x_{k}\right) \in X_{1} \times \ldots \times X_{k}$ such that $D\left(x_{1}, . ., x_{k}\right)=y$.
} 
$q^{* *}=\left(\boldsymbol{x}^{* *}, y^{* *}\right)$ in $\mathcal{X}$ such that: $:^{22}$

(i) $\boldsymbol{x}^{\prime}, \boldsymbol{x}^{\prime \prime}, \boldsymbol{x}^{*}, \boldsymbol{x}^{* *}$ are distinct vectors, $\boldsymbol{x}^{\prime}, \boldsymbol{x}^{\prime \prime}$ are strictly distinct, $\boldsymbol{x}^{*}, \boldsymbol{x}^{* *}$ are strictly distinct, the only difference between $\boldsymbol{x}^{*}$ and $\boldsymbol{x}^{\prime}$ is the estimate on premise-variable 1 where the estimate of variable 1 in $\boldsymbol{x}^{*}$ is the same as in $\boldsymbol{x}^{\prime \prime}$, and the only difference between $\boldsymbol{x}^{* *}$ and $\boldsymbol{x}^{\prime \prime}$ is the estimate on premise-variable 1 where the estimate of variable 1 in $\boldsymbol{x}^{* *}$ is the same as in $\boldsymbol{x}^{\prime}$.

(ii)

$$
\begin{aligned}
\boldsymbol{x}_{m\left(q^{\prime}, q^{\prime \prime}, q^{*}\right)} & =\boldsymbol{x}^{*} \\
\boldsymbol{x}_{m\left(q^{\prime}, q^{\prime \prime}, q^{* *}\right)} & =\boldsymbol{x}^{* *} \\
\boldsymbol{x}_{m\left(q^{*}, q^{* *}, q^{\prime}\right)} & =\boldsymbol{x}^{\prime} \\
\boldsymbol{x}_{m\left(q^{*}, q^{* *}, q^{\prime \prime}\right)} & =\boldsymbol{x}^{\prime \prime}
\end{aligned}
$$

To simplify, and without loss of generality, we put $n=3$. Let $q^{\prime}, q^{\prime \prime}, q^{*}$, $q^{* *}$ be defined as in (i) and (ii).

Suppose $D\left(\boldsymbol{z}^{\prime}\right)=D\left(\boldsymbol{z}^{\prime \prime}\right)$ for any pair of strictly distinct premise vectors. Then $D\left(\boldsymbol{x}^{\prime}\right)=D\left(\boldsymbol{x}^{\prime \prime}\right)$ and $D\left(\boldsymbol{x}^{*}\right)=D\left(\boldsymbol{x}^{* *}\right)$. Then there is a dilemma for at least one profile consisting of exactly three of of the four sequences $q^{\prime}, q^{\prime \prime}$, $q^{*}, q^{* *}$ unless $D\left(\boldsymbol{x}^{\prime}\right)=D\left(\boldsymbol{x}^{\prime \prime}\right)=D\left(\boldsymbol{x}^{*}\right)=D\left(\boldsymbol{x}^{* *}\right)$. The latter can not hold (for all) sequences fulfilling (i) and (ii) when $|Y|>1$.

Suppose $D\left(\boldsymbol{z}^{\prime}\right)>D\left(\boldsymbol{z}^{\prime \prime}\right)$ for at least one pair of strictly distinct premise vectors. We may have 5 cases. We will now show that in all of these cases there is profile $g \in \mathcal{X}^{n}$ such that $D\left(\boldsymbol{x}_{m(g)}\right) \neq y_{m(g)}$.

Case $1 D\left(\boldsymbol{x}^{*}\right) \notin\left[D\left(\boldsymbol{x}^{\prime}\right), D\left(\boldsymbol{x}^{\prime \prime}\right)\right]$. Then $D\left(\boldsymbol{x}_{m(g)}\right) \neq y_{m(g)}$ for $g=\left(q^{\prime}, q^{\prime \prime}, q^{*}\right) \in$ $\mathcal{X}^{n}$.

Case $2 D\left(\boldsymbol{x}^{*}\right) \in\left[D\left(\boldsymbol{x}^{\prime}\right), D\left(\boldsymbol{x}^{\prime \prime}\right)\right\rangle$ and $D\left(\boldsymbol{x}^{* *}\right)<D\left(\boldsymbol{x}^{\prime \prime}\right)$. Then $D\left(\boldsymbol{x}_{m(g)}\right) \neq$ $y_{m(g)}$ for $g=\left(q^{*}, q^{* *}, q^{\prime \prime}\right) \in \mathcal{G}$.

Case $3 D\left(\boldsymbol{x}^{*}\right) \in\left[D\left(\boldsymbol{x}^{\prime}\right), D\left(\boldsymbol{x}^{\prime \prime}\right)\right\rangle$ and $D\left(\boldsymbol{x}^{* *}\right) \geq D\left(\boldsymbol{x}^{\prime \prime}\right)$. Then $D\left(\boldsymbol{x}_{m(g)}\right) \neq$ $y_{m(g)}$ for $g=\left(q^{*}, q^{* *}, q^{\prime}\right) \in \mathcal{G}$.

For the two cases when $D\left(\boldsymbol{x}^{*}\right) \in\left\langle D\left(\boldsymbol{x}^{\prime}\right), D\left(\boldsymbol{x}^{\prime \prime}\right)\right]$, the proof is as for Case 2 and 3.

\section{Proof of Proposition 2}

Put $v_{t}=0$. Then (c.f. (11))

$$
r=D(\kappa)=\frac{1}{\alpha} \frac{\kappa}{\kappa^{2}+\lambda} u_{t} .
$$

\footnotetext{
${ }^{22}$ Example when $k=3: \boldsymbol{x}^{\prime}=(a, b, c), \boldsymbol{x}^{\prime \prime}=(d, e, f), \boldsymbol{x}^{*}=(d, b, c), \boldsymbol{x}^{* *}=(a, e, f)$
} 
$D(\kappa)$ has one only one local maximum (which is also global maximum) if $u_{t}>0$ and only one local minimum (which is also global minimum) if $u_{t}<0$. We only consider the case when $u_{t}>0$ as the proof is parallel if $u_{t}<0$.

Consider a profile $g$. Denote the largest estimate of $\kappa$ in this profile $p^{\max }$, and the smallest element $p^{\min }$. Denote $\arg \max D(p)$ by $p^{*}$. We say that the profile $g$ is dispersed $p^{\min }<p^{*}<p^{\max }$. If $g$ is not dispersed, all estimates of $\kappa$ are on the monotonic part of $D(p)$ and there is no discursive dilemma.

Let $g$ be dispersed. Denote the median estimate of $\kappa$ (among the estimates in the profile $g)$ by $p^{m}$. Note that $D\left(p^{\max }\right)$ and $D\left(p^{\min }\right)$ can not both be bigger than $D\left(p^{m}\right)$ as $D(p)$ is strictly concave. We are left to investigate the following two cases.

Case 1: $D\left(p^{\max }\right)>D\left(p^{m}\right)$ or $D\left(p^{\min }\right)>D\left(p^{m}\right)$. Then $r^{p}=r^{c}$.

Case 2: $D\left(p^{\max }\right)<D\left(p^{m}\right)$ and $D\left(p^{\min }\right)<D\left(p^{m}\right)$. Then $r^{p}>r^{c}$.

\section{References}

Black, Duncan (1948), "On the Rationale of Group Decision-making," The Journal of Political Economy 56(1), 23-34.

Blackorby, Charles, and William Schworm (1984), "The Structure of Economies with Aggregate Measures of Capital: A Complete Characterization," The Review of Economic Studies 51(4), 633-650.

Blin, Jean-Marie, and Mark Satterthwaite (1976), "Strategy-Proofness and Single-Peakedness," Public Choice 26(1), 51-58.

Blinder, Alan S. (2007), "Monetary Policy by Committee: Why and How?" European Journal of Political Economy 23(1), 106-123.

Bovens, Luc, and Wlodek Rabinowicz (2003), "Democracy and Argument Tracking Truth in Complex Social Decisions," in A. van Aaken, C. List, and C. Luetge (eds.), Deliberation and Decision, Aldershot (Ashgate Publishing).

Brainard, William C. (1967), "Uncertainty and the Effectiveness of Policy," The American Economic Review 57(2), 411-425.

Chapman, Bruce (2003), "Rational Choice and Categorical Reason," University of Pennsylvania Law Review 151(3), 1169-1210.

Clarida, Richard, Jordi Gali, and Mark Gertler (1999), "The Science of Monetary Policy: A New Keynesian Perspective," Journal of Economic Literature 37(4), 1661-1707.

Claussen, Carl Andreas, and Øistein Røisland (2010), "A Quantitative Discursive Dilemma," Social Choice and Welfare forthcoming. 
Dietrich, Franz (2007), "A Generalised Model of Judgment Aggregation." Social Choice and Welfare 28(4), 529 - 565.

Dietrich, Franz, and Christian List (2007), "Strategy-proof Judgment Aggregation," Economics and Philosophy 23, 269 - 300.

Faust, Jon, and Dale W. Henderson (2004), "Is Inflation Targeting Bestpractice Monetary Policy?" Federal Reserve Bank of St. Louis Review 86(4), 117-144.

Galí, Jordi (2008), Monetary Policy, Inflation, and the Business Cycle: An Introduction to the New Keynesian Framework, Princeton University Press.

Gerlach-Kristen, Petra (2008), "The Role of the Chairman in Setting Monetary Policy: Individualistic vs Autocratically Collegial MPCs," International Journal of Central Banking 4(3), 119-143.

Kohn, Donald L (2001), "The Kohn Report on MPC Procedures," Bank of England Quarterly Bulletin 41(1), 35-50.

List, Christian (2005), "The Probability of Inconsistencies in Complex Collective Decisions," Social Choice and Welfare 24(1), 3-32.

List, Christian, and Clemens Puppe (2009), "Judgment Aggregation: A Survey," in Anand, P., C. Puppe, and P. Pattanaik (eds.), Oxford Handbook of Rational and Social Choice, Oxford University Press.

List, Cristian (2010), "Judgment Aggregation: A Short Introduction," in Maki, U. (ed.), Handbook of the Philosophy of Economics, Amsterdam (Elsevier), forthcoming.

Meade, Ellen E. (2005), "The FOMC: Preferences, Voting, and Consensus," Federal Reserve Bank of St. Louis Review , 93-101.

Pettit, Philip (2001), "Deliberative Democracy and the Discursive Dilemma," Philosophical Issues (supplement to Nous) 11, 268-99.

Riboni, Alessandro, and Francisco J. Ruge-Murcia (2008), "Preference Heterogeneity in Monetary Policy Committees," International Journal of Central Banking 4(1), 213-233.

Riboni, Alessandro, and Francisco J. Ruge-Murcia (2010), "Monetary Policy by Committee: Consensus, Chairman Dominance or Simple Majority?" Quarterly Journal of Economics forthcoming.

Romer, David H. (2009), "A New Data Set on Monetary Policy: The Economic Forecasts of Individual Members of the FOMC," NBER Working Papers 15208. 
Rubinstein, Ariel, and Peter C. Fishburn (1986), "Algebraic Aggregation Theory," Journal of Economic Theory 38(1), 63-77.

Soderstrom, Ulf (2002), "Monetary Policy with Uncertain Parameters," Scandinavian Journal of Economics 104(1), 125-45.

Svensson, Lars E. O. (2003), "What Is Wrong with Taylor Rules? Using Judgment in Monetary Policy through Targeting Rules," Journal of Economic Literature 41(2), 426-477.

Svensson, Lars E.O. (2010), "Inflation Targeting," in Friedman, Benjamin M., and Michael Woodford (eds.), Handbook of Monetary Economics, vol. $3 \mathrm{a}$ and $3 \mathrm{~b}$, North-Holland, forthcoming.

Tillmann, Peter (2009), "The Fed's Perceived Phillips Curve: Evidence from Individual FOMC Forecasts," Joint Discussion Paper Series in Economics by the Universities of Aachen, GieSSen, Göttingen, Kassel, Marburg, Siegen 200946.

Woodford, Michael (2010), "Forecast Targeting as a Monetary Policy Strategy: Policy Rules in Practice," in Koenig, Evan, and Robert Leeson (eds.), From the Great Moderation to the Great Deviation: A Round-Trip Journey Based on the Work of John B. Taylor, forthcoming.

Yates, J. F. (1990), Judgment and Decision Making, Englewood Cliffs, NJ: Prentice Hall. 


\section{Earlier Working Papers:}

For a complete list of Working Papers published by Sveriges Riksbank, see www.riksbank.se

Estimation of an Adaptive Stock Market Model with Heterogeneous Agents by Henrik Amilon ........ 2005:177

Some Further Evidence on Interest-Rate Smoothing: The Role of Measurement

Errors in the Output Gap by Mikael Apel and Per Jansson.....

Bayesian Estimation of an Open Economy DSGE Model with Incomplete Pass-Through

by Malin Adolfson, Stefan Laséen, Jesper Lindé and Mattias Villani

Are Constant Interest Rate Forecasts Modest Interventions? Evidence from

an Estimated Open Economy DSGE Model of the Euro Area by Malin Adolfson,

Stefan Laséen, Jesper Lindé and Mattias Villani

Inference in Vector Autoregressive Models with an Informative

Prior on the Steady State by Mattias Villani

Bank Mergers, Competition and Liquidity by Elena Carletti, Philipp Hartmann

and Giancarlo Spagnolo

Testing Near-Rationality using Detailed Survey Data

by Michael F. Bryan and Stefan Palmqvist.

Exploring Interactions between Real Activity and the Financial Stance

by Tor Jacobson, Jesper Lindé and Kasper Roszbach

Two-Sided Network Effects, Bank Interchange Fees,

and the Allocation of Fixed Costs by Mats A. Bergman .....

Trade Deficits in the Baltic States: How Long Will the Party Last?

by Rudolfs Bems and Kristian Jönsson.

Real Exchange Rate and Consumption Fluctuations follwing Trade Liberalization

by Kristian Jönsson

Modern Forecasting Models in Action: Improving Macroeconomic Analyses at Central Banks

by Malin Adolfson, Michael K. Andersson, Jesper Lindé, Mattias Villani and Anders Vredin.....

Bayesian Inference of General Linear Restrictions on the Cointegration Space by Mattias Villani.

2005:189

Forecasting Performance of an Open Economy Dynamic Stochastic General Equilibrium Model

by Malin Adolfson, Stefan Laséen, Jesper Lindé and Mattias Villani

Forecast Combination and Model Averaging using Predictive Measures

by Jana Eklund and Sune Karlsson.

Swedish Intervention and the Krona Float, 1993-2002

by Owen F. Humpage and Javiera Ragnartz

A Simultaneous Model of the Swedish Krona, the US Dollar and the Euro

by Hans Lindblad and Peter Sellin

Testing Theories of Job Creation: Does Supply Create Its Own Demand?

by Mikael Carlsson, Stefan Eriksson and Nils Gottfries.....

Down or Out: Assessing The Welfare Costs of Household Investment Mistakes

by Laurent E. Calvet, John Y. Campbell and Paolo Sodini

Efficient Bayesian Inference for Multiple Change-Point and Mixture Innovation Models

by Paolo Giordani and Robert Kohn

Derivation and Estimation of a New Keynesian Phillips Curve in a Small Open Economy

by Karolina Holmberg

Technology Shocks and the Labour-Input Response: Evidence from Firm-Level Data

by Mikael Carlsson and Jon Smedsaas

Monetary Policy and Staggered Wage Bargaining when Prices are Sticky

by Mikael Carlsson and Andreas Westermark

The Swedish External Position and the Krona by Philip R. Lane

Price Setting Transactions and the Role of Denominating Currency in FX Markets

by Richard Friberg and Fredrik Wilander.....

The geography of asset holdings: Evidence from Sweden

by Nicolas Coeurdacier and Philippe Martin

Evaluating An Estimated New Keynesian Small Open Economy Model

by Malin Adolfson, Stefan Laséen, Jesper Lindé and Mattias Villani .......

The Use of Cash and the Size of the Shadow Economy in Sweden

by Gabriela Guibourg and Björn Segendorf

Bank supervision Russian style: Evidence of conflicts between micro- and macro-

prudential concerns by Sophie Claeys and Koen Schoors 
Optimal Monetary Policy under Downward Nominal Wage Rigidity

by Mikael Carlsson and Andreas Westermark.

Financial Structure, Managerial Compensation and Monitoring

by Vittoria Cerasi and Sonja Daltung

Financial Frictions, Investment and Tobin's q by Guido Lorenzoni and Karl Walentin

Sticky Information vs. Sticky Prices: A Horse Race in a DSGE Framework

by Mathias Trabandt.

Acquisition versus greenfield: The impact of the mode of foreign bank entry

on information and bank lending rates by Sophie Claeys and Christa Hainz

Nonparametric Regression Density Estimation Using Smoothly Varying Normal Mixtures

by Mattias Villani, Robert Kohn and Paolo Giordani

The Costs of Paying - Private and Social Costs of Cash and Card

by Mats Bergman, Gabriella Guibourg and Biörn Segendorf.

Using a New Open Economy Macroeconomics model to make real nominal

exchange rate forecasts by Peter Sellin

Introducing Financial Frictions and Unemployment into a Small Open Economy Model

by Lawrence J. Christiano, Mathias Trabandt and Karl Walentin.....

Earnings Inequality and the Equity Premium by Karl Walentin

2007:215

Bayesian forecast combination for VAR models by Michael $K$ Andersson and Sune Karlsson $2007: 216$

Do Central Banks React to House Prices?

by Daria Finocchiaro and Virginia Queijo von Heideken

The Riksbank's Forecasting Performance

by Michael K. Andersson, Gustav Karlsson and Josef Svensson

Macroeconomic Impact on Expected Default Freqency

by Per Åsberg and Hovick Shahnazarian

Monetary Policy Regimes and the Volatility of Long-Term Interest Rates

by Virginia Queijo von Heideken

Governing the Governors: A Clinical Study of Central Banks

by Lars Frisell, Kasper Roszbach and Giancarlo Spagnolo

The Monetary Policy Decision-Making Process and the Term Structure of Interest Rates

by Hans Dillén

How Important are Financial Frictions in the U.S. and the Euro Area

by Virginia Queijo von Heideken

Block Kalman filtering for large-scale DSGE models by Ingvar Strid and Karl Walentin 2008:224

Optimal Monetary Policy in an Operational Medium-Sized DSGE Model

by Malin Adolfson, Stefan Laséen, Jesper Lindé and Lars E.O. Svensson

Firm Default and Aggregate Fluctuations by Tor Jacobson, Rikard Kindell, Jesper Lindé and Kasper Roszbach

Re-Evaluating Swedish Membership in EMU: Evidence from an Estimated Model

by Ulf Söderström

The Effect of Cash Flow on Investment: An Empirical Test of the Balance Sheet Channel

by Ola Melander

Expectation Driven Business Cycles with Limited Enforcement

by Karl Walentin ...

Effects of Organizational Change on Firm Productivity

by Christina Håkanson

Evaluating Microfoundations for Aggregate Price Rigidities: Evidence from Matched Firm-Level

Data on Product Prices and Unit Labor Cost by Mikael Carlsson and Oskar Nordström Skans

Monetary Policy Trade-Offs in an Estimated Open-Economy DSGE Model

by Malin Adolfson, Stefan Laséen, Jesper Lindé and Lars E.O. Svensson

Flexible Modeling of Conditional Distributions Using Smooth Mixtures of Asymmetric

Student T Densities by Feng Li, Mattias Villani and Robert Kohn......

Forecasting Macroeconomic Time Series with Locally Adaptive Signal Extraction

by Paolo Giordani and Mattias Villani.....

Evaluating Monetary Policy by Lars E.O. Svensson

Risk Premiums and Macroeconomic Dynamics in a Heterogeneous Agent Model

by Ferre De Graeve, Maarten Dossche, Marina Emiris, Henri Sneessens and Raf Wouters $2010: 236$

Picking the Brains of MPC Members by Mikael Apel, Carl Andreas Claussen and

Petra Lennartsdotter

Involuntary Unemployment and the Business Cycle by Lawrence J. Christiano,

Mathias Trabrandt and Karl Walentin

Housing collateral and the monetary transmission mechanism by Karl Walentin

and Peter Sellin 
Sveriges Riksbank

Visiting address: Brunkebergs torg 11

Mail address: se-103 37 Stockholm

Website: www.riksbank.se

Telephone: +46878700 00, Fax: +468210531

E-mail: registratorn@riksbank.se 